\title{
Análise de uma Proposta Metodológica para Uso das Tecnologias Digitais no Ambiente Escolar
}

\author{
Cícero Bandeira Lima Filho ${ }^{1}$, José Aires de Castro Filho ${ }^{2}$ \\ ${ }^{1}$ Secretaria Municipal da Educação de Quixadá \\ ${ }^{2}$ Instituto UFC Virtual - Universidade Federal do Ceará (UFC) \\ cicerobandeira@yahoo.com.br, aires@virtual.ufc.br
}

\begin{abstract}
: the present work analyzes the contributions of a methodological proposal that guides in the use of digital technologies in the school environment presupposing the active participation of students and the collaboration between teachers and them. Throughout the intervention, it was generated data from the analyzes of interaction between the participants in designs production times and animations to represent High School Biology content, using the Squeak application. The carried study allowed to establish: an increase interaction between students, involvement and reflection about the studied contents, brainstorming and shared elaboration of knew knowledge.
\end{abstract}

\begin{abstract}
Resumo: o presente trabalho analisa as contribuições de uma proposta metodológica que orienta o uso das tecnologias digitais no ambiente escolar tendo como pressuposto a participação ativa dos estudantes e da colaboração entre eles e o professor. No decorrer da intervenção, foram gerados dados a partir das análises das interações entre os participantes nos momentos de produção de desenhos e animações para representar conteúdos de Biologia do Ensino Médio, utilizando o aplicativo Squeak. O estudo realizado permitiu constatar: aumento das interações entre estudantes, envolvimento e reflexão sobre o conteúdo estudado, troca de ideias e elaboração compartilhada de novos saberes.
\end{abstract}

Palavras-chaves: Tecnologias digitais, colaboração, Ensino de Biologia.

\section{Introdução}

As tecnologias digitais fazem parte do cotidiano de maneira muito intensa. Foram incorporadas ao dia-a-dia de variadas formas, atendendo às demandas impostas pelo mundo contemporâneo. No ambiente escolar já foram objeto de diversas pesquisas acerca do seu potencial para contribuir com os processos de ensino e de aprendizagem e das melhores estratégias para serem integradas às salas de aula das nossas escolas.

O fazer pedagógico nas escolas brasileiras ainda tem como característica a predominância da "didática da transmissão", da "pedagogia do discurso" e da "transmissão desprovida de contexto" (BRASIL, 2002, p.11). O professor ainda ocupa um papel muito central, colocando os alunos numa posição de passividade (SAVIANI, 
2010). No contexto escolar com essas características, a inserção das tecnologias digitais proporciona poucos benefícios em relação ao potencial educacional destes recursos.

Apenas a presença de computadores em sala de aula não oferece contribuições relevantes aos processos de ensino e de aprendizagem. Há sempre o risco de serem utilizados dentro de uma perspectiva tradicional de educação, reforçando o modelo transmissor de informações, mantendo a postura passiva do aluno sem incentivá-lo a utilizar os instrumentos computacionais de forma colaborativa.

Kenski (2007, p. 87), aponta a seguinte ressalva: "o simples uso de tecnologias não altera significativamente os espaços físicos das salas de aula e nem as dinâmicas utilizadas para ensinar e aprender". É necessário associar o uso dos recursos computacionais à estratégias didáticas diferenciadas.

Corroborando com as ideias anteriores, Berens (2007, p. 99), destaca, "O recurso por si só não garante inovação, mas depende de um projeto bem arquitetado, alimentado pelos professores e alunos que são usuários".

Diante dos argumentos apresentados que enfatizam as limitações e empecilhos ao aproveitamento do potencial educacional dos recursos tecnológicos, constata-se a necessidade de se desenvolver propostas metodológicas em que as tecnologias digitais sejam integradas ao ambiente escolar numa perspectiva diferente do que acontece no ambiente tradicional de educação.

Na proposta metodológica adotada neste trabalho, o computador foi utilizado a partir de estratégias didáticas baseadas na colaboração e na participação ativa dos alunos, dando suporte à representação de conteúdos escolares através da criação de desenhos e animações.

Para viabilizar a realização do trabalho, foi utilizado o aplicativo Squeak, disponível no laptop educacional presente em escolas participantes do Projeto Um Computador por Aluno (UCA) e teve como sujeitos participantes, estudantes de uma escola estadual do Município de Quixadá-Ceará, organizados em pares, que criaram desenhos e animações para representar conteúdos de Biologia do $3^{\circ}$ ano do Ensino Médio.

Diante das considerações apresentadas anteriormente, configuram-se como objetivos centrais deste trabalho:

- Analisar as contribuições de uma proposta metodológica de utilização das tecnologias digitais baseada no trabalho colaborativo com suporte de tecnologias digitais;

- Identificar indícios de que a intervenção realizada interfere no estudo dos conteúdos escolares de Biologia no $3^{\circ}$ ano do Ensino Médio.

O presente trabalho está organizado nas seguintes sessões: introdução, com descrição breve do presente trabalho; método, que detalha os procedimentos metodológicos, necessários à realização da pesquisa, resultados alcançados e conclusões obtidas.

\section{Método}

O presente estudo optou por uma abordagem qualitativa, que tem caráter descritivo e explicativo e levou em conta não apenas dados numéricos, sobretudo os significados 
obtidos nas interações acontecidas entre os sujeitos participantes. Quanto ao envolvimento do pesquisador, caracteriza-se como uma pesquisa-intervenção, que segundo Damiani (2012), partem de uma intenção de mudança ou inovação, constituindo-se, em práticas a serem analisadas; trabalham com dados criados, em contraposição a dados já existentes, que são simplesmente coletados.

Damiani (2012, p. 03) destaca ainda que são:

[...] interferências (mudanças, inovações) propositadamente realizadas, por professores/pesquisadores, em suas práticas pedagógicas. Tais interferências são planejadas e implementadas com base em um determinado referencial teórico e objetivam promover avanços, melhorias, nessas práticas, além de pôr à prova referencial, contribuindo para o avanço do conhecimento sobre os processos de ensino/aprendizagem neles envolvidos.

A intervenção realizada na escola teve por pressuposto a criação de situações didáticas em que os estudantes foram incentivados a adotarem postura ativa e colaborativa na discussão e representação de problemas de ciências usando suporte das tecnologias digitais.

A proposta metodológica citada neste trabalho consistiu na utilização das seguintes estratégias didáticas:

$\checkmark$ Exposição dialogada do conteúdo pelo pesquisador (que assumiu o papel do professor);

$\checkmark$ Criação de animação, em pares de alunos, para representar o conteúdo de Biologia, através do aplicativo Squeak;

$\checkmark$ Apresentação das animações criadas pelos alunos para o professor e os colegas;

$\checkmark$ Intervenção do pesquisador através de perguntas, questionamentos, instigando a reflexão e a colaboração entre os pares.

Das estratégias didáticas listadas anteriormente, os momentos de criação e socialização das animações tiveram especial relevância, pois produziram os dados que possibilitaram as análises e conclusões.

Foram organizadas e realizadas 08 intervenções, abordando os seguintes conteúdos disciplinares de Biologia: fotossíntese, cadeia alimentar, fluxo de energia, ciclos biogeoquímicos: ciclo da água e do carbono, efeito estufa e poluição. Nestes momentos o pesquisador assumiu a função de professor, ministrando as aulas sobre os conteúdos citados, como está descrito anteriormente quando é tratado das estratégias didáticas utilizadas.

O trabalho foi realizado numa escola situada em Quixadá, município do sertão central do Estado do Ceará. Situada numa área intermediária entre zona urbana e rural do referido município, atendendo a um público-alvo, que em grande parte provém da zona rural, com pouco acesso aos recursos tecnológicos digitais.

Os sujeitos da pesquisa foram 06 alunos do $3^{\text {o }}$ ano do Ensino Médio, selecionados a partir do critério de disponibilidade para participar das intervenções realizadas no contra turno.

Foram usadas duas técnica de geração de dados: 
V Congresso Brasileiro de Informática na Educação (CBIE 2016)

Anais do XXII Workshop de Informática na Escola (WIE 2016)

a) Observação e registro em diário de campo: utilizados para acompanhar o trabalho nos grupos e verificar como se deu o processo de colaboração entre os pares e deste com os demais colegas. Foi observado também como os estudantes lidavam com a ferramenta utilizada e os conteúdos de Biologia escolhidos.

b) Registro em áudio e vídeo: buscou registrar o trabalho no interior dos grupos e nos momentos de socialização das animações. Foi um instrumento complementar às observações do pesquisador e permitiu analisar de forma minuciosa as interações estabelecidas entre os participantes e destes com os conteúdos disciplinares e a ferramenta escolhida.

Os diversos dados coletados foram confrontados com referencial teórico adotado gerando as reflexões que serão apresentadas a seguir.

\section{Resultados}

Os resultados do presente trabalho estão organizados em torno das contribuições aos processos de ensino e de aprendizagem.

A proposta metodológica adotada neste trabalho favoreceu o surgimento de interações entre os estudantes. $\mathrm{O}$ fato dos estudantes terem sido provocados a criar, ao invés de apenas assistirem aulas expositivas se constituiu num estímulo à troca de ideias. Os dois momentos principais de observação do pesquisador, a elaboração de animações em pares e a socialização das animações são evidências do quanto a participação dos estudantes foi ampliada, como é possível observar no exemplo a seguir.

A figura 01 mostra uma animação criada para representar o ciclo do carbono. $\mathrm{Na}$ apresentação, os alunos demonstraram ter percebido as relações de causa de efeito entre a poluição atmosférica e seu impacto sobre a intensificação do efeito estufa e seus efeitos sobre o derretimento das calotas polares.

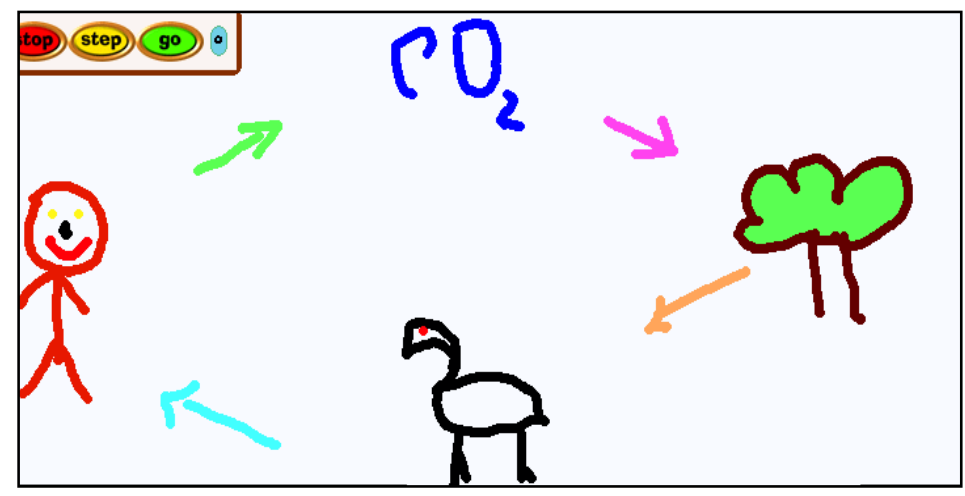

Figura 1: animação criada pelos estudantes para representar o ciclo do carbono.

O excerto 01, que apresenta as falas deste momento revela o que as estudantes conseguiram perceber.

Excerto 01: O vídeo transcrito foi coletado na $6^{\mathrm{a}}$ aplicação da pesquisa. Nele consta o registro do momento da socialização do desenho criado, por um dos pares que tinha por objetivo representar o ciclo do carbono. 
V Congresso Brasileiro de Informática na Educação (CBIE 2016)

Anais do XXII Workshop de Informática na Escola (WIE 2016)

1 - Aluna M2: o carbono está na atmosfera, a árvore absorve e passa pro pato (animal indicado na animação), do pato passa pra pessoa e a pessoa passa novamente o gás carbônico na atmosfera. Aí fica nesse ciclo... indo e voltando...

2 - P: como é que a pessoa libera esse gás carbônico, através de que?

Aluna M2: da respiração?!

Já no excerto 02, (trechos 11, 12 e 13) uma das participantes comenta as relações entre a poluição do ar e o efeito estufa.

Excerto 02: O vídeo transcrito foi coletado na $8^{\mathrm{a}}$ aplicação da pesquisa. Neste momento foi proposto a criação de animação para representar diferentes formas de poluição. Nele consta o registro do planejamento previsto por um dos pares, a fim de realizar a atividade a eles proposta.

1 - P: o que vocês tão pensando de fazer ?

2 - (a afirmação a seguir é feita indicando o desenho criado no laptop)

3 - Aluna M: tipo uma indústria, uma casinha, bem por aqui assim, aí jogando o esgoto.

4 - Aluna C: tu falou sobre poluição da água?

5 - Aluna M: é

6 - Aluna C: falei do ar... só se botar assim... tipo uma indústria ... aí solta fumaça e o esgoto para dentro da água.

7 - (P pediu que deixassem mais claro o que a dupla propunham fazer)

8 - Aluna M: ela falou sobre a poluição do ar e eu falei sobre a poluição da água.

9 - Aluna C: a gente vai juntar as duas coisas e criar uma só.

10 - P: detalhem como será a animação a ser criada

11 - Aluna M: a gente vai juntar os dois, fazendo uma fábrica poluindo o ar e soltando esgoto dentro do rio e sendo assim polui o ar pra gente e polui os rios pros animais morrerem, como os peixes. Não tem comida pros outros se alimentarem.

12 - P pergunta: de que forma essa ideia de vocês se relaciona com o que estudamos aqui durante esses oito encontros?

13 - Aluna C pede a palavra, levantando a mão e diz: "tem, na parte que eu falei, na poluição do ar, afeta o ar que a gente respira, isso vai ajudando no efeito estufa."

As situações analisadas mostram que os estudantes interagiram, compartilharam ideias e tomaram decisões sobre como proceder diante dos desafios que lhes foram propostos. Torres e Irala (2007) destacam que as práticas colaborativas têm como característica o engajamento mútuo e o esforço coordenado. No excerto 03 , apresentado a seguir, observa-se na ação conjunta das alunas, negociação e coordenação de pensamentos a fim de preparar a execução da tarefa que lhes foi proposta.

Os trechos 03 e 08 , do excerto 02 , descrevem as ideias iniciais das alunas e revelam que cada uma dispunha de perspectiva diferente a respeito do que representar, entretanto a partir das interações estabelecidas chegou-se a um consenso, capaz de unificar a proposta de solução para o desafio lançado, como se pode verificar nos trechos 09, 10 11. Constata-se desta forma o que foi dito pelos autores, anteriormente, que as situações colaborativas favorecem o engajamento mútuo e esforço.

O trecho apresentado anteriormente evidencia uma das características das situações de colaboração, a co-construção do conhecimento (JEONG, 1997). De uma 
situação inicial em que cada estudante tinha uma ideia particular de como representar as formas de poluição que atingem o meio ambiente se chegou a uma proposta que resultou na junção entre as ideias de ambos, ou seja, a ideia final é resultante do compartilhamento das ideias individuais iniciais. Nesta mesma perspectiva, Jeong (1997) também destaca a importância da representação compartilhada no sentido de contribuir para aprendizagem.

As transcrições apresentadas no excerto 03, também confirmam as formulações de Damiani (2008) a respeito da importância do trabalho conjunto, do apoio recíproco, da confiança mútua e da co-responsabilidade na realização das ações. Ao partilhar a responsabilidade pela atividade, os estudantes chegaram ao entendimento comum a respeito do percurso a ser adotado e ampliaram a ideia inicial.

O papel do outro e das interações sociais são destacadas por Vygotsky (2007), como essenciais à aprendizagem. As sequências apresentadas a seguir evidenciam a importância das trocas estabelecidas pelos pares no sentido de formar novas ideias a respeito de um tema estudado.

No excerto 03 (trechos de 5 a 11) as participantes relacionam o ciclo da água à poluição dos rios e à necessidade do zelo pelo ambiente onde se vive. Percebem também que a degradação dos rios interfere na cadeia alimentar provocando desequilíbrios.

Questionados sobre como fariam a animação proposta pelo pesquisador, os alunos responderam:

Excerto 03: $\mathrm{O}$ vídeo transcrito foi coletado na $8^{\mathrm{a}}$ aplicação da pesquisa. Nele consta o registro do momento em que os pares comentam como será criada a animação para representar as diferentes formas de poluição.

1 - Aluna L: a gente vai apresentar o que a gente aprendeu, só que no Squeak... a gente encontra muito do dia-a-dia a poluição nos rios... aí eu queria demonstrar.

2 - P: que conteúdos você relaciona com a poluição dos rios, do que vocês estudaram até aqui?

3 - Aluno J: o meu dá pra relacionar porque eu fiz da... eu fiz a poluição dos combustíveis fósseis, dos veículos, aí da pra relacionar com os gases do efeito estufa.

4 - P: e a animação que vocês pretendem criar no Squeak, de que forma ela se relaciona com o que a gente estudou nesse tempo aqui?

5 - Aluna L: um conteúdo que eu achei muito interessante foi o ciclo da água... quando chove não forma o rio?! Nesse rio, poderíamos aproveitar de outra forma, não jogando lixo.

6 - P: Tô entendendo, a questão da poluição dos rios com o ciclo da água, não é?! Mas aí, eu teria uma pergunta a fazer... nós estudamos a cadeia alimentar, não foi?! Será que ela se relaciona de alguma forma com a poluição dos rios? 7 - Alunos permanecem pensativos...

8 - P: de que forma a poluição dos rios interfere na cadeia alimentar?

9 - Aluna L: ahhh... (expressão de admiração) com o derramamento de petróleo no rio, os peixes vão morrer, eu pensei desta forma.

10 - P: to acompanhando o seu raciocínio... e como ela interfere mais?

11 - Aluno J: interfere na... se matar ... me ajuda aluna L... se matar um certo tipo de peixe, o que se alimenta dele também vai entrar em extinção.

12 - Aluna L: Justamente, aluno J! Comemora 
Das interações estabelecidas entre os alunos e destes com o professor surgiu a constatação de que a poluição interfere e tem consequências para a cadeia alimentar. Constata-se desta forma a importância das trocas estabelecidas entre os diversos participantes do processo de ensino-aprendizagem.

Por esta nova perspectiva o processo de ensino e aprendizagem ganha um caráter coletivo em detrimento do que habitualmente acontece no cotidiano escolar, predominantemente marcado por ações individuais e/ou competitivas. Observa-se nas transcrições apresentadas que a relação que se estabeleceu entre os participantes foi determinante para as novas constatações a que chegaram os estudantes.

A atuação do mais experiente na aquisição de novos saberes tem grande destaque nas formulações de Vygotsky (2007). No contexto de sala de aula esse papel pode ser desempenhado tanto pelo professor, quanto por colegas, que num determinado momento, tenham adquirido maior conhecimento a respeito de uma temática específica.

O excerto 03 retrata uma situação em que os participantes, inicialmente, possuem compreensões diferentes. Da divergência inicial se chega à junção dos pontos de vista. Surgiu uma nova constatação que é mais abrangente do que a soma das percepções iniciais. O fato dos estudantes dialogarem sobre o conteúdo estudado, trocarem ideias e formularem novas compreensões da questão indicam que a ação coletiva possibilitou os estudante a irem além do que podiam fazer individualmente.

A sintonia que surgiu entre os participantes favoreceu o surgimento de novas compreensões e possibilitou aos estudantes adentrar no que Vygotsky (2007) concebe como ZDP. Esse espaço simbólico de comunicação e interação, como é tratado por Meira e Lerman (2001) ou, ainda, espaço simbólico de construção compartilhada, como é retratado por Colaço (2001) possibilitou o surgimento uma concepção comum a todos, que vai além da soma das compreensões individuais.

Outra constatação decorrente da pesquisa refere-se à ferramenta utilizada. Destaca-se, dentre os benefícios proporcionados pela ferramenta Squeak, o suporte para materialização das ideias dos estudantes, realizado através da criação dos desenhos e animações. Tal fato facilitou a interação entre os pares e a intervenção do professor, já que permitiu a expressão dos saberes que cada um dispunha e, desta forma, a socialização e troca de entendimentos sobre saberes e percursos adotados.

A utilização do Squeak numa perspectiva de suporte à criação coletiva trouxe a possibilidade de superação do modelo de simples memorização de conceitos, aplicação de técnicas repetitivas e transmissão de conteúdos. Os diversos excertos apresentados neste trabalho evidenciam mudanças nas posturas docentes e discentes.

Constatou-se também alguns benefícios ao processo de aprendizagem de Biologia: envolvimento com a atividade, entusiasmo e colaboração entre os participantes. As animações criadas contribuíram para romper com a passividades dos estudantes e do processo criativo decorreu uma série de reflexões acerca dos conteúdos estudados.

Valente (2011) as atividades mediadas pelo Squeak, tornam os mais alunos empenhados com a tarefa. O autor também observou entusiasmo e interações com a professora no sentido de mostrar suas produções, o que mostra uma atitude positiva com a situação didática vivenciada. 
V Congresso Brasileiro de Informática na Educação (CBIE 2016)

Anais do XXII Workshop de Informática na Escola (WIE 2016)

Todas as contribuições relatadas neste trabalho evidenciam a relevância da pesquisa realizada.

\section{Conclusões}

A inserção das tecnologias digitais ao processo de ensino-aprendizagem não garante a renovação das práticas docentes e discentes. É necessário associar o uso das TIC à metodologias que fomentem a participação dos estudantes e a superação da perspectiva individual de aprender, buscando desenvolver estratégias colaborativas.

É necessário também romper com alguns resquícios do modelo tradicional de educação, manifestados na dificuldade para colaborar. Observou-se, inicialmente, grande resistência ao compartilhamento e envolvimento dos estudantes nas situações didáticas criadas. Prevalecia, principalmente no início, a tendência à divisão de tarefas, em que cada um assumia a responsabilidade por uma parcela do problema. Somente com a sequências das intervenções e aplicação das novas estratégias didáticas foi possível atingir os objetivos almejados.

A atuação docente foi decisiva diante da necessidade inicial de romper com o desinteresse pelo estudo das ciências. Nem mesmo a ferramenta tecnológica com seus atrativos por si só garante o encantamento pela Biologia. O envolvimento esperado foi surgindo na medida em que os estudantes foram se apropriando dos saberes que estavam envolvidos nas atividades. Neste sentido a atuação insistente e mediadora docente promoveu as aproximações necessárias e o despertar do gosto por esta importante área de saber.

Dentre as contribuições da ferramenta tecnológica ressalta-se o fato desta proporcionar aos estudantes a criação dos objetos, como os desenhos e animações. Este fato mudou a relação dos estudantes com o objeto de estudo e com o pesquisador, que na ocasião também atuou como docente. $\mathrm{O}$ acompanhamento do processo de criação e depois de socialização das produções foram momentos ricos de trocas de entendimentos e dúvidas entre os estudantes, além da intervenção docente. Referindo-se a utilização de aplicativos como Squeak num contexto de sala de aula, Shäffer, Sperb e Fagundes (2011, p. 9) apontam "resultados mais efetivos em relação à construção do conhecimento e ao desenvolvimento conceitual do aluno quando há mudanças pedagógicas em sala de aula".

Neste caso a utilização de uma tecnologia digital que permite criar, recriar, incorporar objetos de outros contextos viabiliza a expressão do pensamento e a partir dela, o confronto de ideias e as trocas tão relevantes à aquisição de novos saberes. Neste sentido a perspectiva individual cede lugar à atuação coletiva, em os pares interagem na busca de elaborar conhecimentos comuns.

\section{Referências}

BRASIL (2002). Secretaria da Educação Média e Tecnológica. PCN + Ensino Médio: Orientações Educacionais complementares aos Parâmetros Curriculares Nacionais. Brasília: MEC/SEMTEC.

BERENS, M. A. (2000) . Projetos de Aprendizagem Colaborativa num Paradigma Emergente In: MORAN, José Manuel. Novas Tecnologias e Mediação Pedagógica. Campinas, SP: Papirus. 
V Congresso Brasileiro de Informática na Educação (CBIE 2016)

Anais do XXII Workshop de Informática na Escola (WIE 2016)

COLAÇO, V. et Al. (2002). Estratégias de mediação em situação de interação entre crianças em sala de aula. Estud. psicol. (Natal) [online]. vol.12, n.1, pp. 47-56. ISSN 1413-294X. http://dx.doi.org/10.1590/S1413-294X2007000100006.

DAMIANI, M. (2008). Trabalho colaborativo/cooperativo em educação: uma possibilidade para ensinar e aprender. Brasília: Liber Livro.

DAMIANI, M. (2012). Sobre pesquisas do tipo intervenção. XVI Encontro Nacional de Didática e Práticas de Ensino (ENDIPE). Campinas.

KENSKI, V. M. (2007). Educação e Tecnologias: o novo ritmo da informação. Campinas: Papirus.

JEONG, H.; CHI, M. T. H. (1997). Construction of shared knowledge during collaborative learnig. In: R. HALL, R.; MIYAKE, N.; ENYEDY, J. (Ed.). International Conference On Computer Support For Collaborative Learning, 2., Toronto, 1997. Annals... Toronto, p. 1-5.

GÓES, C. ; SMOLKA, L. (1997). A significação nos espaços educacionais: interação social e subjetivação. São Paulo: Papirus.

MASSETO, M. Mediação Pedagógica e o Uso da Tecnologia In: MORAN, José Manuel. Novas Tecnologias e Mediação Pedagógica. Campinas, SP: Papirus, 2000.

MEIRA, L. ; LERMAN, S. (2001). The Zone of Proximal Development as a symbolic space. Social Science Research Papers, Londres, UK, 13, 1-12,

SAVIANI, D. (2010). História das Ideias Pedagógicas no Brasil. $3^{\text {a }}$ ed. Campinas, SP, Autores Associados.

SHÄFFER, P.B; SPERB, B.F; FAGUNDES, L.C. (2011) Squeak Etoys na modalidade 1 para 1: programação e autoria multimídia no desenvolvimento da conceituação. SIMPÓSIO BRASILEIRO DE INFORMÁTICA NA EDUCAÇÃO. 22, Aracaju. Anais.... p. 1226-1235.

TORRES, P. L. (2007). Algumas vias para entender o pensar e o agir. Curitiba: SENAR-PR.

VYGOTSKY. L. S. (2007) A formação social da mente: o desenvolvimento dos processos psicológicos superiores. $7^{\mathrm{a}}$ ed. São Paulo: Martins Fontes.

WOOD, D. (2003). Como as crianças pensam e aprendem: os contextos sociais do desenvolvimento cognitivo. São Paulo: Edições São Paulo: Loyola. 